\title{
The Cannabinoid Agonist Win55212 Reduces Brain Damage in an In Vivo Model of Hypoxic-Ischemic Encephalopathy in Newborn Rats
}

\author{
DAVID FERNÁNDEZ-LÓPEZ, M. RUTH PAZOS, ROSA M. TOLÓN, M. ANGELES MORO, JULIÁN ROMERO, \\ IGNACIO LIZASOAIN, AND JOSÉ MARTÍNEZ-ORGADO
}

\begin{abstract}
Departamento de Farmacología [D.F.-L., M.A.M., I.L.], Facultad de Medicina, Universidad Complutense, 28040 Madrid, Spain; Laboratorio de Apoyo a la Investigación [M.R.P., R.M.T., J.R.]; Área de Pediatría y Neonatología [J.M.-O.], Fundación Hospital Alcorcón, 28922 Alcorcón, Madrid, Spain
\end{abstract}

\begin{abstract}
Neonatal hypoxic-ischemic encephalopathy (NHIE) is a devastating condition for which effective therapeutic treatments are still unavailable. Cannabinoids emerge as neuroprotective substances in adult animal studies; therefore, we aimed herein to test whether cannabinoids might reduce brain damage induced by hypoxiaischemia (HI) in newborn rats. Thus, 7-d-old Wistar rats (P7) were exposed to $8 \% \mathrm{O}_{2}$ for $120 \mathrm{~min}$ after left carotid artery ligature, then received s.c. vehicle $(\mathrm{VEH})(\mathrm{HI}+\mathrm{VEH})$, the cannabinoid agonist WIN55212 (WIN) $(0.1 \mathrm{mg} / \mathrm{kg})$, or WIN with the $\mathrm{CB}_{1}$ or $\mathrm{CB}_{2}$ receptor antagonist SR141617 (SR1) (3 mg/kg) or SR141588 (SR2) $(2 \mathrm{mg} / \mathrm{kg}$ ). Brain damage was assessed by magnetic resonance imaging (MRI) at 1, 3, and $7 \mathrm{~d}$ after the insult. At the end of the experiment, MRI findings were corroborated by histology (Nissl staining). HI $+\mathrm{VEH}$ showed an area of cytotoxic and vasogenic edema at $24 \mathrm{~h}$ after the insult, then evolving to necrosis. HI+WIN showed a similar damaged area at $24 \mathrm{~h}$ after the insult, but the final necrotic area was reduced by $66 \%$. Coadministration of either SR 1 or $\mathrm{SR} 2$ reversed the effects of WIN. In conclusion, likely by activating $\mathrm{CB}_{1}$ and $\mathrm{CB}_{2}$ receptors, WIN afforded robust neuroprotection in newborn rats after HI. (Pediatr Res 62: 255-260, 2007)
\end{abstract}

$\mathrm{N}^{\mathrm{n}}$ HIE remains as a prevalent condition, inducing devastating brain injury leading to death or long-lasting sequelae $(1,2)$. Despite recent progress in neonatology, the incidence of NHIE is not decreasing, likely because the complex pathophysiology of NHIE demands combined therapies or the use of treatments acting at different levels, as hypothermia (1,3-5). In addition, due to the current inability to predict accurately perinatal asphyxia, only a posteriori treatments are feasible $(1,2)$.

Cannabinoids and their receptors constitute an endogenous system involved, for instance, in the control of synaptic transmission, memory modulation, motivation, movement, nociception, appetite, and thermoregulation $(6,7)$. Two cannabinoid receptors present in the brain have been cloned so far: $\mathrm{CB}_{1}$ receptors are expressed primarily by neurons but can also

Received March 6, 2007; accepted April 9, 2007

Correspondence: José Martínez-Orgado, M.D., Ph.D., Area de Pediatría y Neonatología, Fundación Hospital Alcorcón, Budapest, 1, 28922-Alcorcón, Madrid, Spain; e-mail: jamartinezo@fhalcorcon.es

This work was supported by grants from FIS-PI061085 (J.M.-O.), FIS-PI021540 (J.M.-O.), Premio FHA-Fundación Mapfre Medicina 2005 (J.M.-O.), SAF2006-01753 (M.A.M.), SAF 2004-00237 (J.R.), and SAF2005-05960 (I.L.). be found in glial cells; $\mathrm{CB}_{1}$ receptors are Gi/o proteincoupled receptors that modulate the activity of several plasma membrane proteins and intracellular signaling pathways $(7,8)$. $\mathrm{CB}_{2}$ receptors are also Gi/o protein-coupled receptors; although it is accepted that $\mathrm{CB}_{2}$ receptors are not expressed in forebrain neurons, they have been described in activated glia (8-10). Lately, cannabinoids are emerging as valuable neuroprotective agents in models of acute and chronic neurodegenerative conditions $(6,7,11-15)$, which may also affect the immature rat brain (16).

Due to this evidence, we decided to test whether cannabinoids might be useful for decreasing brain damage in NHIE. For this purpose, we used the Rice-Vannucci model (17), an in vivo model that closely mimics actual NHIE conditions. Importantly, we assessed the effect of WIN when administered after the onset of the HI insult. To evaluate brain damage, we used MRI, an approach with several advantages: (1) MRI allows the development of imaging-based longitudinal studies, providing important data on the response time and on the mechanisms of action of the investigated therapeutic strategy (18), and (2) MRI has been proposed as a surrogate measure of brain damage, as the extent of the injury determined by MRI matches well with that determined by histology $(19,20)$.

\section{MATERIALS AND METHODS}

Induction of HI brain damage. $\mathrm{P} 7$ Wistar rat pups were used in all the experiments, which adhered to the guidelines of the Animal Welfare Committee of the Universidad Complutense of Madrid (following EU directives 86/609/CEE and 2003/65/CE). To induce HI brain damage, we followed the protocol we described previously (21), except that after left carotid artery ligature, pups were now exposed to $8 \% \mathrm{O}_{2}$ and $92 \% \mathrm{~N}_{2}$ for $120 \mathrm{~min}$ to accomplish the Rice-Vannucci model (17). Three pups died during the HI procedure. Between 5 and $10 \mathrm{~min}$ after recovery, each surviving pup was randomly assigned to one experimental group, receiving one s.c. dose of VEH (0.5\% DMSO in PBS, $100 \mu \mathrm{L} / 20 \mathrm{~g})(\mathrm{HI}+\mathrm{VEH}, n=26)$; WIN $(0.1 \mathrm{mg} / \mathrm{kg})$ $(\mathrm{HI}+\mathrm{WIN}, n=18)$; WIN + the $\mathrm{CB}_{1}$ receptor antagonist SR1 $(3 \mathrm{mg} / \mathrm{kg})$ $(\mathrm{HI}+\mathrm{WIN}+\mathrm{SR} 1, n=7)$; or WIN + the $\mathrm{CB}_{2}$ receptor antagonist SR2 (2 $\mathrm{mg} / \mathrm{kg})(\mathrm{HI}+\mathrm{WIN}+\mathrm{SR} 2, n=6)$. WIN and the corresponding antagonist were administered simultaneously. Doses were selected following previous studies from several groups including ours $(16,21)$. Each experimental group con-

Abbreviations: ADC, apparent diffusion coefficient; DWI, diffusion weighted images; NHIE, neonatal hypoxic-ischemic encephalopathy; SR1, SR141617; SR2, SR141588; T2WIs, T2-weighted images; WIN, R (+)-WIN$552122-2$ 
tained pups from at least three different litters. A third group of pups underwent a sham operation with neither carotid ligature nor $8 \% \mathrm{O}_{2}$ exposure, remaining the control group (CTL, $n=7)$. Fourteen pups died after HI (10 $\mathrm{HI}+\mathrm{VEH}$, three $\mathrm{HI}+\mathrm{WIN}$, and one $\mathrm{HI}+\mathrm{WIN}+\mathrm{SR} 1)$.

MRI. For the MRI study (performed in the MRI Unit, Instituto Pluridisciplinar, Universidad Complutense de Madrid), we selected $\mathrm{T}_{2}$-weighted images ( $\mathrm{T}_{2}$ WIs) and diffusion-weighted images (DWIs), which are usually preferred for this purpose $(18,19,22-24)$. Although $\mathrm{T}_{2} \mathrm{WI}$ is useful to quantify the final brain damage $(19,23)$, DWI is sensitive to intercompartmental water shifts, thus being useful to evaluate functional impairment and recovery from the very early moments after $\mathrm{HI}(18,19,24-26)$. An MRI study was performed in all animals (seven CTL, $16 \mathrm{HI}+\mathrm{VEH}, 15 \mathrm{HI}+\mathrm{WIN}$, six HI+WIN+SR1, and six $\mathrm{HI}+\mathrm{WIN}+\mathrm{SR} 2) 1,3$, and $7 \mathrm{~d}$ after $\mathrm{HI}$ or the equivalent period in the CTL group. These time points are commonly used in studies of ischemic brain injury in rat pups $(18,20,22,23)$. The study at $\mathrm{P} 8$ analyzed early brain damage $(18,20,22,23)$; at P14, the final extent of damage was determined $(18,20,22,23)$. Study at P10 is selected as an intermediate point $(18,20,22,23)$. During MRI, the animals were kept in a thermoregulated animal holder under anesthesia with $0.5 \%$ fluothane administered by a hood to prevent pup movements but avoiding hypoxemia; anesthesia was withdrawn just at the end of the MRI. All measurements were performed on a BIOSPEC BMT 47/40 (Bruker-Medical, Ettlingen, Germany) operating at $4.7 \mathrm{~T}$, equipped with an avoid actively shielded gradient insert with an $11.2-\mathrm{cm}$ bore, a maximal gradient strength of $200 \mathrm{mT} / \mathrm{m}$, an $80-\mu$ s rise time, and a home-made $4-\mathrm{cm}$ surface coil. $\mathrm{T}_{2} \mathrm{WI}$ was acquired with a multislice rapid acquisition $(\mathrm{TR}=$ $3.4 \mathrm{~s}$, RARE factor $=8$, interecho interval $=30 \mathrm{~ms}$, TEeff $=120 \mathrm{~ms}$; matrix size $=256 \times 256($ pixel dimensions $117 \times 117 \mu \mathrm{m})$, field of view $(\mathrm{FOV})=$ $\left.3 \mathrm{~cm}^{2}\right)$. DWI was performed with stimulated echoes $(\mathrm{TE}=80 \mathrm{~ms}, \mathrm{TR}=2 \mathrm{~s}$, DW factor b from 41.5 to $1029.5 \mathrm{~s} / \mathrm{mm}^{2}$, matrix size $=128 \times 64, \mathrm{FOV}=3$ $\mathrm{cm}^{2}$ ). The slice package consisted of 13 consecutive slices for the $T_{2}$ WIs and eight for DWI of $1.0 \mathrm{~mm}$ slice thickness in the axial plan interleaved by a $0.2-\mathrm{mm}$ gap, covering the entire brain.

The fractional extent of brain edema or infarction was calculated from MR images on each slice and summed to yield the entire volume of the lesion. Area of injury was calculated in each slice using the ImageJ $1.34 \mathrm{~s}$ software (U.S. National Institutes of Health). In $\mathrm{T}_{2}$ WIs, vasogenic edema and tissue liquefaction appeared hyperintense. The extent of the lesion size was determined by measuring the hyperintense area in $\mathrm{T}_{2}$ WIs at P8, P10, and P14, and was expressed as the percentage of total brain volume. The brain regions were identified from MRI by comparison with standard histologic slices from an appropriate atlas (27). To calculate quantitative apparent diffusion coefficient (ADC) maps, a single-slice, single-shot sequence consisting of diffusionsensitized spin echo followed by a RARE loop for signal acquisition was used. Data for eight images with respective b values of $5,45,101,180,282$, 406,552 , and $718 \mathrm{~s} / \mathrm{mm}^{2}$ were acquired from a $2.5-\mathrm{mm}$-thick axial slice placed at the level of the pineal recess of the third ventricle. Phase and amplitude correction was applied to the raw data before calculating the images. Finally, the ADC was calculated for each pixel using a linear fit to the natural logarithm of the pixel intensities of the different images as a function of the $\mathrm{b}$ value, and ADC maps devoid of $\mathrm{T}_{2}$ effects were reconstructed in a matrix size of $128 \times 64$ covering an FOV of $3 \times 3 \mathrm{~cm}$. For quantitative diffusion evaluation, the mean ADC values were obtained from the calculated ADC maps; ADC measurements were performed in ipsilateral parietal cortex in circular regions of interest (ROIs) of $1.5-\mathrm{mm}$ diameter. The deviation of the pixel-by-pixel analysis within the ROI was $<100 \mu \mathrm{m}^{2} / \mathrm{s}$.

Histologic study. The histopathologic study was performed in all animals, as described elsewhere (21). Briefly, brains fixed in $4 \%$ paraformaldehyde and frozen at $-70^{\circ} \mathrm{C}$ were cut with a cryostat $\left(-20^{\circ} \mathrm{C}\right)$ in coronal sections. Six $40-\mu \mathrm{m}$ thick slices were obtained across the rostral hippocampus starting from the point correspondent to $+2.3 \mathrm{~mm}$ anterior to the interaural zero point following the appropriate atlas (27). To study brain damage, brain sections were stained using the Nissl technique.

Chemicals and statistical analyses. SR141716 and SR144528 were a generous gift from Sanofi-Synthelabo (Paris, France). The other chemicals were from Sigma Chemical Co. (Madrid, Spain).

Results are expressed as mean \pm SEM of the indicated number of experiments. Statistical comparisons of injury volumes or ADC values were made using analysis of variance (ANOVA), with the Scheffé test for multiple comparisons. A $p$ value $<0.05$ was considered as statistically significant. Statistical analysis was performed using the 11.0.0 version of SPSS software (SPSS Inc.).

\section{RESULTS}

Resonance magnetic imaging. HI induced ipsilateral hemisphere atrophy at P14, as shown by the decreased hemisphere volume $(22.2 \pm 2.1 \%)$ calculated in $\mathrm{HI}+\mathrm{VEH}$. This effect was reduced in animals treated with the agonist cannabinoid WIN $(11.3 \pm 1.6 \%$; ANOVA $p=0.01$ versus $\mathrm{HI}+\mathrm{VEH})$. Either SR1 or SR2 reversed the effect of WIN (ipsilateral hemisphere atrophy: $17.9 \pm 1.1 \%$ for $\mathrm{HI}+\mathrm{WIN}+\mathrm{SR} 1$, ANOVA $p=$ 0.484 versus $\mathrm{HI}+\mathrm{VEH}$, and $20.2 \pm 1.1 \%$ for $\mathrm{HI}+\mathrm{WIN}+\mathrm{SR} 2$, ANOVA $p=0.941$ versus $\mathrm{HI}+\mathrm{VEH})$.

$\mathrm{HI}$ also caused brain necrosis. In HI+VEH, $\mathrm{T}_{2}$ WIs $24 \mathrm{~h}$ after HI revealed an extensive hyperintense area (Fig. 1), corresponding with vasogenic edema $(18,20,22,23)$. At P14, a hyperintense area of similar extension was still observable (Fig. 1), corresponding with permanent cell death $(18,22,23)$. In HI+WIN $24 \mathrm{~h}$ after $\mathrm{HI}, \mathrm{T}_{2} \mathrm{WI}$ revealed a hyperintense area similar to that observed in $\mathrm{HI}+\mathrm{VEH}$, but this area evolved to a smaller area, usually hypointense (Fig. 1). Figure 2 depicts the evolution of the damaged area for each animal. In $\mathrm{HI}+\mathrm{WIN}$, the reduction of the area of damage was significant $3 \mathrm{~d}$ after $\mathrm{HI}(23.1 \pm 4 \%$ versus $7.3 \pm 4.2 \%$ in $\mathrm{HI}+\mathrm{VEH}$, ANOVA $p<0.05)$, and evolved to a $67.5 \pm 1.9 \%$ of reduction at $\mathrm{P} 14$ (versus $19.1 \pm 2.8 \%$ in $\mathrm{HI}+\mathrm{VEH}$, ANOVA $p<0.05$ ) (Fig. 2). Either SR1 or SR2 prevented the effect of WIN, so that in these cases, $\mathrm{T}_{2}$ WIs appear similar to $\mathrm{HI}+\mathrm{VEH}$ both in extent and time course (Figs. 1 and 2).

In DWIs, HI+VEH showed a hyperintense area $24 \mathrm{~h}$ after HI (Fig. 3), corresponding to cytotoxic edema (18,24-26). The coincidence of hyperintense areas in DWIs and $\mathrm{T}_{2}$ WIs
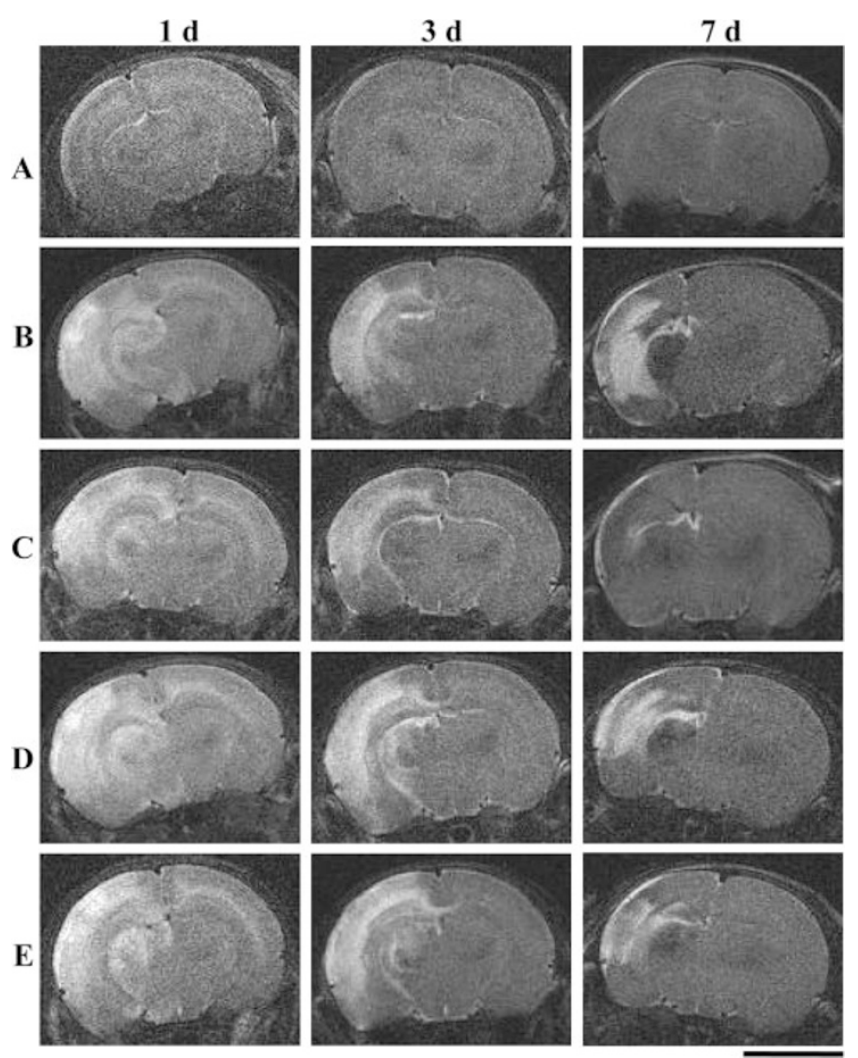

Figure 1. Representative evolution of brain injury with MRI $\mathrm{T}_{2}$ WIs in 7-d-old rat pups exposed to $8 \% \mathrm{O}_{2}$ for $120 \mathrm{~min}$ after left common carotid artery ligature, receiving VEH $(B)$, WIN55212 $(C)$, WIN+SR1 $(D)$, or WIN+SR2 $(E)$. (A) Control pups underwent a sham operation. Images were taken 1,3 , and $7 \mathrm{~d}$ after insult. Hyperintensities at $1 \mathrm{~d}$ represent vasogenic edema, whereas at $7 \mathrm{~d}$ they represent tissue loss. Bar $=5 \mathrm{~mm}$. 


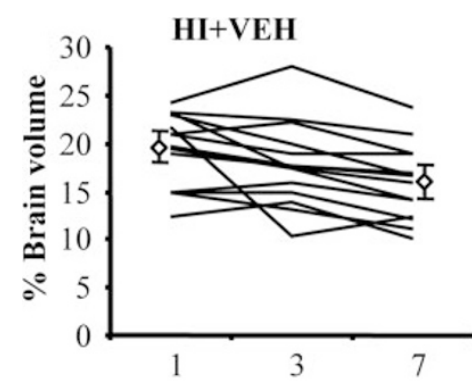

HI+WIN

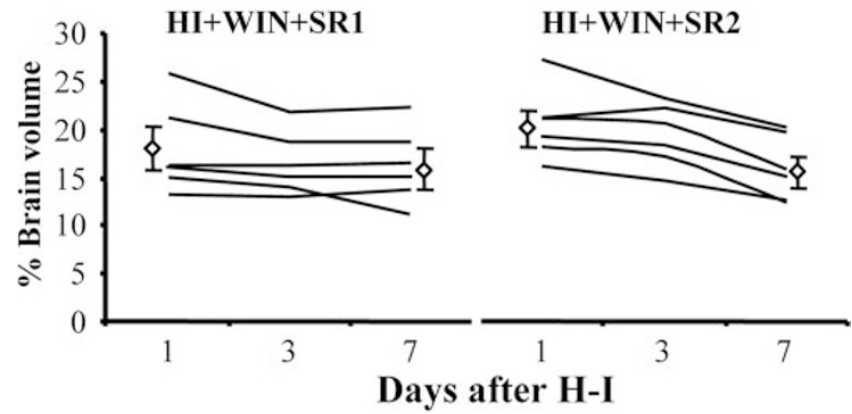

Figure 2. Evolution of the volume of injured area, calculated from MRI $\mathrm{T}_{2}$ WIs obtained from 7-d-old rat pups exposed to $8 \% \mathrm{O}_{2}$ for $120 \mathrm{~min}$ after left common carotid artery ligature, receiving VEH (HI+VEH), WIN55212 $(\mathrm{HI}+\mathrm{WIN}), \mathrm{WIN}+\mathrm{SR} 1(\mathrm{HI}+\mathrm{WIN}+\mathrm{SR} 1)$, or $\mathrm{WIN}+\mathrm{SR} 2(\mathrm{HI}+\mathrm{WIN}+\mathrm{SR} 2)$. Lines represent values calculated 1,3 , and $7 \mathrm{~d}$ after insult in the same animal. Plotted diamonds represent the mean (SEM) of values obtained 1 and $7 \mathrm{~d}$ after insult. *ANOVA $p<0.05 v s \mathrm{HI}+\mathrm{VEH}$.
$1 \mathrm{~d}$
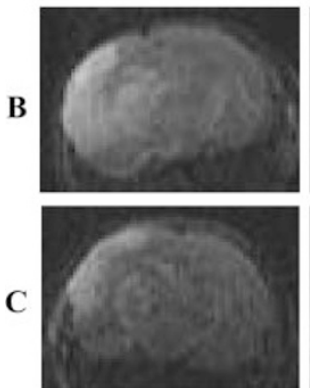

D
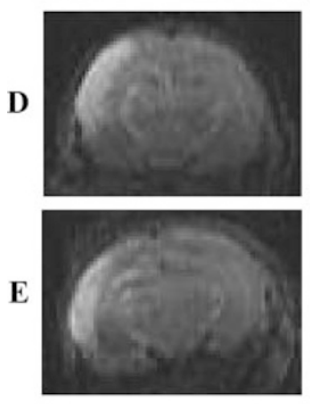

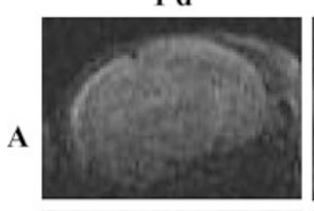

$3 d$
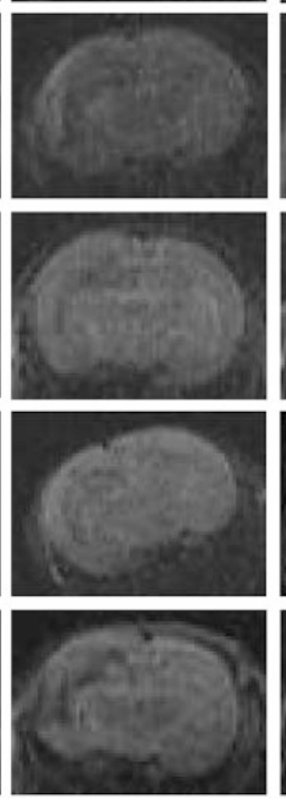

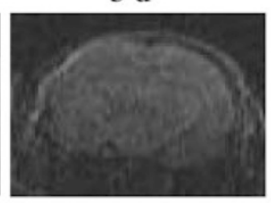

$7 \mathrm{~d}$
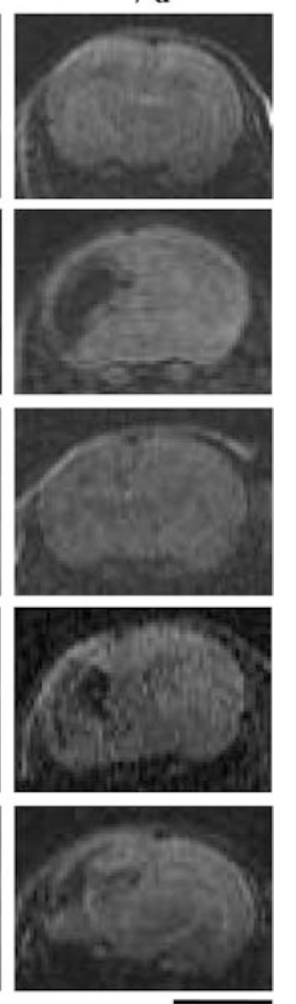

Figure 3. Representative evolution of brain injury with MR DWI in 7-d-old rat pups exposed to $8 \% \mathrm{O}_{2}$ for $120 \mathrm{~min}$ after left common carotid artery ligature, receiving VEH $(B)$, WIN55212 $(C), \mathrm{WIN}+\mathrm{SR} 1(D)$ or WIN + SR2 $(E)$. Control pups $(A)$ underwent a sham operation. Images were taken 1,3 , and $7 \mathrm{~d}$ after insult. Hyperintensities represent cytotoxic edema, whereas hypointensities represent vasogenic edema and tissue loss. Bar $=5 \mathrm{~mm}$.
Table 1. Evolution of brain ADC values in cortex

\begin{tabular}{llll}
\hline & \multicolumn{1}{c}{$1 \mathrm{~d}$} & \multicolumn{1}{c}{$3 \mathrm{~d}$} & \multicolumn{1}{c}{$7 \mathrm{~d}$} \\
\hline $\mathrm{CTL}$ & $0.90(0.02)$ & $0.94(0.04)$ & $0.86(0.02)$ \\
$\mathrm{HI}+\mathrm{VEH}$ & $0.49(0.06)^{*}$ & $0.80(0.04)$ & $1.47(0.09)^{*}$ \\
$\mathrm{HI}+\mathrm{WIN}$ & $0.45(0.03)^{*}$ & $0.84(0.06)$ & $0.81(0.03) \dagger$ \\
$\mathrm{HI}+\mathrm{WIN}+$ SR1 & $0.40(0.03)^{*}$ & $0.84(0.07)$ & $1.31(0.09)^{*}$ \\
$\mathrm{HI}+\mathrm{WIN}+$ SR2 & $0.44(0.05)^{*}$ & $0.92(0.09)$ & $1.15(0.09)^{*}$ \\
\hline
\end{tabular}

Values obtained from 7-d-old rat pups exposed to $8 \% \mathrm{O}_{2}$ for $120 \mathrm{~min}$ after left common carotid artery ligature, treated with VEH $(\mathrm{HI}+\mathrm{VEH})$, WIN55212 (HI+WIN), WIN+SR1 (HI+WIN+SR1) or WIN+SR2 $(\mathrm{HI}+\mathrm{WIN}+\mathrm{SR} 2)$. CTL pups underwent a sham operation. Values were calculated 1, 3, and $7 \mathrm{~d}$ after insult. Results are the mean (SEM) of values obtained from five to 15 animals, expressed as $10^{-5} \cdot \mathrm{cm}^{2} \cdot \mathrm{s}^{-1}$.

* ANOVA, $p<0.05$ vs CTL.

$\dagger$ ANOVA, $p<0.05 v s$ the other HI groups.

demonstrate the coexistence of cytotoxic and vasogenic edema $24 \mathrm{~h}$ after $\mathrm{HI}(18,22-24)$. Hyperintensity evolved to an apparent normalization at P10, corresponding to an increase in vasogenic edema and to glial cell edema (24-26). Finally, injured area evolved to hypointensity at P14, indicating cell death, as water is moving more freely due to the destruction of cellular membranes $(24,26)$. In HI+WIN, DWIs revealed a hyperintense area similar to that of HI+VEH $24 \mathrm{~h}$ after $\mathrm{HI}$; in this case, however, the area recovered the normal signal at P14 (Fig. 3). Either SR1 or SR2 prevented the effect of WIN, with DWIs showing damaged areas similar in extent and evolution to those of HI+VEH (Fig. 3).

To quantify changes in diffusion, ADC values in parietal cortex were calculated for each animal, obtaining the mean of values from three different ROIs. ADC values remained stable during the study period in CTL, with values around $1 \times 10^{-5}$ $\mathrm{cm}^{2} / \mathrm{s}(23,26,28)$. In HI+VEH, ADC evolved from values near $50 \%$ of control when measured $24 \mathrm{~h}$ after HI, corresponding to a restricted water mobility because of the cytotoxic edema, to supranormal values at P14, corresponding to a mobility near to free water due to cell death $(24,26)$ (Table 1$)$. The analysis of ADC values corroborated the evolution to recovery of the area of cytotoxic edema by WIN: in HI+WIN, $\mathrm{ADC}$ values $24 \mathrm{~h}$ after $\mathrm{HI}$ were similar to those of $\mathrm{HI}+\mathrm{VEH}$. In this case, however, ADC evolved to values similar to those of CTL at P14 (Table 1). Either SR1 or SR2 reversed the effect of WIN (Table 1).

Histology. The histopathologic study performed in brain slices at P14 corroborated the findings of MRI. In HI+VEH, ipsilateral ventricle size appeared increased, suggesting a significant atrophy of brain tissue (Fig. 4); in addition, there was a dramatic reduction of the density of cellular bodies in cortex, mainly consisting of pyknotic cells. In HI+WIN, atrophy was reduced, as revealed by an only modest increase of ventricle size, and cortex cellular density was substantially spared, with neuronal cell bodies appearing well preserved (Fig. 4). Either SR1 or SR2 reversed the effect of WIN (Fig. 4).

\section{DISCUSSION}

We have explored the neuroprotective effect of the cannabinoid agonist WIN in a standard newborn rat model of NHIE (Rice-Vannucci model), demonstrating that WIN successfully 

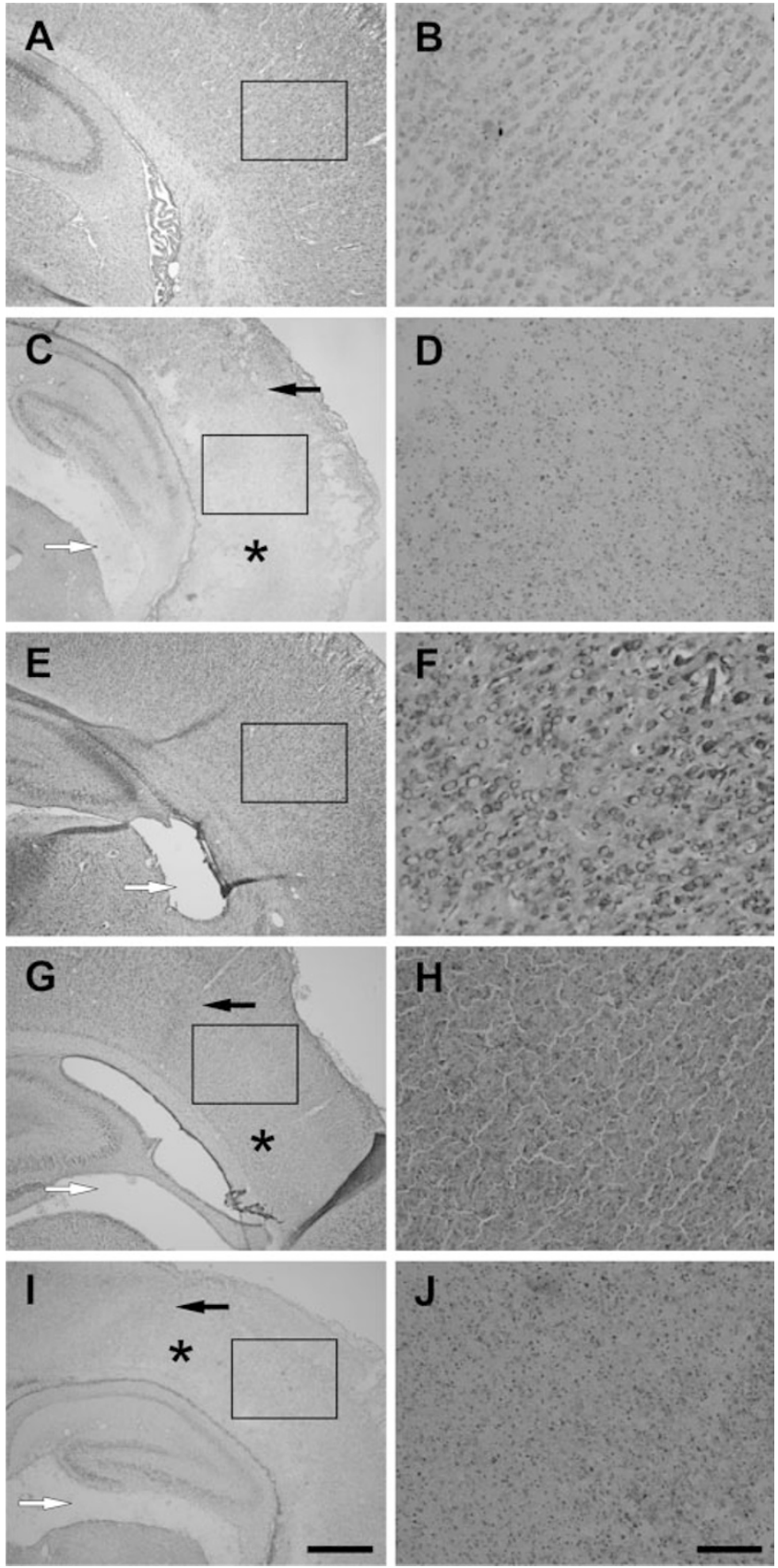

Figure 4. Representative light microphotographs of Nissl-stained brain sections, obtained $7 \mathrm{~d}$ after sham operation $(A, B)$ or after $\mathrm{HI}$ from rat pups receiving VEH $(C, D)$, WIN55212 $(E, F)$, WIN+SR1 $(G, H)$ or WIN+SR2 $(I, J)$. $(A, C, E, G, I)$ : original magnification $\times 40$, bar: $1 \mathrm{~mm}$; right column $(B$, $D, F, H, J)$ : further magnification of selected areas $(\times 200$, bar $=100 \mu \mathrm{m})$. In brain administered $\mathrm{HI}+\mathrm{VEH}$, an ischemic border is apparent (black arrows), delineating an area of damage (asterisks) devoid of neuronal cell bodies except some pyknotic neurons; in the damaged hemisphere, there is a loss of cortical volume as represented by the increased ventricular size (white arrows). Administration of WIN reduced the damage, this effect being reversed by coadministration of SR1 or SR2.

reduces brain injury. This result agrees with previous studies on neuroprotection by cannabinoids in different in vivo models of acute brain injury (6) in adult animals including global or focal ischemia (15) and closed head injury (14) or in newborn animals after excitotoxic injury (16). To our knowledge, our data are the first to demonstrate the neuroprotective effect of a cannabinoid agonist using the Rice-Vannucci model. The importance of the present results may be highlighted by (1) the strong efficacy of WIN administration; (2) the fact that WIN was useful being administered after the HI insult, which renders this strategy feasible in actual clinical conditions where NHIE is almost unpredictable (1); and (3) the demonstration of the participation of $\mathrm{CB}_{2}$ receptors in the neuroprotective effect of WIN, which gives insights into the pharmacologic profile of those cannabinoids that could be used in this condition.

Our study was completed $7 \mathrm{~d}$ after the insult, although evolution of ischemic brain damage is not completed at that point. Nevertheless, time-course studies indicate that cell loss reaches a maximum about $4-7 \mathrm{~d}$ after ischemia in newborn rat brain, decreasing thereafter as a spontaneous gradual recovery occurs (29). In addition, a recent long-term follow-up study of ischemic brain injury using MRI in untreated newborn rats by Ashwal et al. (20) demonstrated that the lesion volume at $7 \mathrm{~d}$ after injury is not significantly different from that at $28 \mathrm{~d}$. Thus, to assess the neuroprotective effect of a given strategy, studies at P14 are appropriate. In our study, the volume of brain damage shown by MRI $24 \mathrm{~h}$ after HI was lower than that found by Ashwal et al. (20) [40\% of brain hemisphere damaged versus $60 \%$ in Ashwal et al. (20)]. This can be due to the different sensitivity of the MRI devices used [4.7 $\mathrm{T}$ in our study, 11.7 T in the Ashwal et al. (20) study]. By contrast, the volume of brain damage $7 \mathrm{~d}$ after $\mathrm{HI}$ was almost twofold greater in our study, likely reflecting a more severe injury in our experiments due to a longer hypoxic period [120 $\mathrm{min}$ of $8 \% \mathrm{O}_{2}$ versus $90 \mathrm{~min}$ in the Ashwal et al. (20) study]. In this scenario, the neuroprotective effect observed herein by administering WIN after HI was very significant, reducing the volume of lesion present $7 \mathrm{~d}$ after the injury by about $67 \%$.

There are few reports evaluating the neuroprotective effect of a given strategy after HI using MRI. Some of these reports have described a reduction by $42 \%-65 \%$ of the injured area when using hypothermia as neuroprotective strategy $(30,31)$, a proportion very similar to that obtained with WIN. In addition, WIN reduced the shrinkage of the ipsilateral hemisphere observed after HI. Ipsilateral hemisphere shrinkage is a characteristic feature of this model of EHIN in newborn rats (32). Cannabinoids show several properties, which may explain their neuroprotective effect. We have demonstrated that WIN reduces glutamate and cytokine release as well as toxic nitric oxide production in newborn rat brain after HI (33). These effects of WIN are due to the reduction of calcium influx and the inhibition of transcriptional factors expression, among others (13). The mentioned effects are of special significance as glutamate and cytokine release and toxic nitric oxide production play a key role in the cascade of events leading to neuronal death in newborn brain (1-4). In addition, cannabinoids show different properties with neuroprotective potential: they induce an anti-inflammatory effect, reduce $\alpha$-amino-3hydroxy-5-methyl-4-isoxazole propionicacid (AMPA)kainate receptor mediate excitotoxicity, are antioxidant and vasodilators, stabilize the blood-brain barrier, and induce hypothermia $(6,7,11,12,14,16,34)$. 
Our results support the importance of $\mathrm{CB}_{1}$ receptor activation in the neuroprotective effect of cannabinoids, as we have reported after severe acute anoxia in rats (21). In addition, our results demonstrate for the first time the involvement of $\mathrm{CB}_{2}$ receptors in the neuroprotective effect of cannabinoids in acute neonatal $\mathrm{HI}$ brain damage in vivo. A recent report demonstrated that the administration of $\mathrm{CB}_{2}$ agonists after transient middle cerebral artery occlusion in mice reduces the extent of cerebral infarction (35). The relevance of these findings derives from the knowledge that $\mathrm{CB}_{2}$ receptor activation does not elicit psychoactive effects (7), a fact of major importance regarding the possibility of using cannabinoids in humans. More excitingly, we have found that the neuroprotective effect of WIN depends on the activation of both $\mathrm{CB}_{1}$ and $\mathrm{CB}_{2}$ receptors, as either SR1 or SR2 administration prevented the effects of WIN. This agrees with what we recently described in an in vitro model of NHIE (33) as well as in a model of excitotoxicty in the brain (36). Recent reports have described the presence of $\mathrm{CB}_{2}$ receptors in brain cells (8-10,37-39); in agreement, we have demonstrated by Western blot the presence of $\mathrm{CB}_{2}$ receptors in forebrain slices (33) and whole-brain homogenates (Fernandez-Lopez et al., unpublished data, 2006) from 7-d-old rats. In the brain, forebrain neurons are known to express $\mathrm{CB}_{1}$ but not $\mathrm{CB}_{2}$ receptors (7). Activated astrocytes and microglial cells, however, may express both $\mathrm{CB}_{1}$ and $\mathrm{CB}_{2}$ receptors $(9,10,38,40)$; less is known about $\mathrm{CB}$ receptor expression and functionality in oligodendrocytes (8). Some relevant actions of cannabinoids on astrocytes and microglial cells seem to be mediated by the activation of both $\mathrm{CB}$ receptors. Thus, the blockade of either $\mathrm{CB}_{1}$ or $\mathrm{CB}_{2}$ receptors abolishes cannabinoid-induced modulation of the toxic production of nitric oxide and cytokines by cultured astrocytes or microglial cells $(39,41)$. These data altogether suggest an important role for glial cells in the neuroprotective effect induced by WIN in our experiments. Astrocytes play some important supportive roles for neuronal survival under normal conditions and in particular during brain ischemia, as astrocytes scavenge glutamate and free radicals, modulate water transport as well as cytokines and nitric oxide production, and influence neuron regeneration (42). In agreement, Docagne et al. (36) elegantly demonstrated that cannabinoids prevent AMPA-induced cell injury in mixed cortical cultures from mice by simultaneously activating $\mathrm{CB}_{1}$ receptors in neurons and $\mathrm{CB}_{2}$ receptors in astrocytes. The role of resting microglia under normal conditions is not clear; after an insult, however, activated microglia play a key role in the inflammatory process inducing brain damage (43). Interestingly, $\mathrm{CB}_{1}$ and $\mathrm{CB}_{2}$ receptors are constitutively expressed and functional in the endothelial cells of human brain microvessels (44); it is then attractive to hypothesize that an enhancement of brain microcirculation after $\mathrm{HI}$ could be involved in WIN-induced neuroprotection, a possibility that deserves further investigation.

In conclusion, the administration of the cannabinoid agonist WIN to newborn rats after an HI insult afforded a robust neuroprotective effect. This effect is dependent on the activation of both $\mathrm{CB}_{1}$ and $\mathrm{CB}_{2}$ receptors. The magnitude of the protective effect, together with the important role of receptors unlinked to psychoactive effects, open exciting perspectives for cannabinoids as a feasible tool against acute postischemic neurodegeneration.

Acknowledgments. The authors thank Encarnación Valle and David Castejón from the MRI Unit of the Instituto Pluridisciplinar de la Universidad Complutense de Madrid for the performance of the magnetic resonance studies.

\section{REFERENCES}

1. Volpe JJ 2001 Hypoxic-ischemic encephalopathy: clinical aspects. In: Volpe JJ (ed) Neurology of the Newborn. WB Saunders, Philadelphia, pp 331-394

2. Vannucci RC, Perlman JM 1997 Interventions for perinatal hypoxic-ischemic encephalopathy. Pediatrics 100:1004-1014

3. Ferriero DM 2004 Neonatal brain injury. N Engl J Med 351:1985-1995

4. Martinez-Orgado J, Fernandez-Lopez D, Moro MA, Lizasoain I 2006 Nitric Oxide synthase as a target for the prevention of hypoxic-ischemic newborn brain damage. Curr Enzym Inhib 2:219-229

5. Edwards AD, Azzopardi DV 2006 Therapeutic hypothermia following perinatal asphyxia. Arch Dis Child Fetal Neonatal Ed 91:F127-F131

6. Mechoulam R, Panikashvili D, Shohami E 2002 Cannabinoids and brain injury: therapeutic implications. Trends Mol Med 8:58-61

7. Howlett AC, Breivogel C, Childers SR, Deadwyler SA, Hampson RE, Porrino LJ 2004 Cannabinoid physiology and pharmacology: 30 years of progress. Neuropharmacology 47:345-358

8. Stella N 2004 Cannabinoid signaling in glial cells. Glia 48:267-277

9. Maresz K, Carrier EJ, Ponomarev ED, Hillard CJ, Dittel BN 2005 Modulation of the cannabinoid CB receptor in microglial cells in response to inflammatory stimuli. J Neurochem 95:437-445

10. Benito C, Romero JP, Tolon RM, Clemente D, Docagne F, Hillard CJ, Guaza C, Romero J 2007 Cannabinoid CB1 and CB2 receptors and fatty acid amide hydrolase are specific markers of plaque cell subtypes in human multiple sclerosis. J Neurosci 27:2396-2402

11. Marsicano G, Goodenough S, Monory K, Hermann H, Eder M, Cannich A, Azad SC, Cascio MG, Gutierrez SO, van der Stelt M, Lopez-Rodriguez ML, Casanova E, Schutz G, Zieglgansberger W, Di Marzo V, Behl C, Lutz B 2003 CB1 cannabinoid receptors and on-demand defense against excitotoxicity. Science 302:84-88

12. Klein TW 2005 Cannabinoid-based drugs as anti-inflammatory therapeutics. Nat Rev Immunol 5:400-411

13. Martinez Orgado JA, Fernandez López D, Bonet Serra B, Lizasoain Hernandez I, Romero Paredes J 2005 [The cannabinoid system and its importance in the perinatal period]. An Pediatr (Barc) 63:433-440

14. Panikashvili D, Shein NA, Mechoulam R, Trembovler V, Kohen R, Alexandrovich A, Shohami E 2006 The endocannabinoid 2-AG protects the blood-brain barrier after closed head injury and inhibits mRNA expression of proinflammatory cytokines. Neurobiol Dis 22:257-264

15. Nagayama T, Sinor AD, Simon RP, Chen J, Graham SH, Jin K, Greenberg DA 1999 Cannabinoids and neuroprotection in global and focal cerebral ischemia and in neuronal cultures. J Neurosci 19:2987-2995

16. van der Stelt M, Veldhuis WB, van Haaften GW, Fezza F, Bisogno T, Bar PR, Veldink GA, Vliegenthart JF, Di Marzo V, Nicolay K 2001 Exogenous anandamide protects rat brain against acute neuronal injury in vivo. J Neurosci 21:8765-8771

17. Rice JE, Vannucci RC, Brierley JB 1981 The influence of immaturity on hypoxicischemic brain damage in the rat. Ann Neurol 9:131-141

18. Weber R, Ramos-Cabrer P, Hoehn M 2006 Present status of magnetic resonance imaging and spectroscopy in animal stroke models. J Cereb Blood Flow Metab 26:591-604

19. Derugin N, Dingman A, Wendland MF, Fox C, Bollen A, Vexler ZS 2005 Magnetic resonance imaging as a surrogate measure for histological sub-chronic endpoint in a neonatal rat stroke model. Brain Res 1066:49-56

20. Ashwal S, Tone B, Tian HR, Chong S, Obenaus A 2007 Comparison of two neonatal ischemic injury models using magnetic resonance imaging. Pediatr Res 61:9-14

21. Martinez-Orgado J, Fernandez-Frutos B, Gonzalez R, Romero E, Uriguen L, Romero J, Viveros MP 2003 Neuroprotection by the cannabinoid agonist WIN-55212 in an in vivo newborn rat model of acute severe asphyxia. Brain Res Mol Brain Res 114:132-139

22. Albensi BC, Schweizer MP, Rarick TM, Filloux F 1999 Unilateral hypoxic-ischemic injury in the neonatal rat brain evaluated by in vivo MRI. Correlation with histopathology and neuroprotection by MK-801. Invest Radiol 34:249-261

23. Nedelcu J, Klein MA, Aguzzi A, Boesiger P, Martin E 1999 Biphasic edema after hypoxic-ischemic brain injury in neonatal rats reflects early neuronal and late glial damage. Pediatr Res 46:297-304

24. Fiehler J, Fiebach JB, Gass A, Hoehn M, Kucinski T, Neumann-Haefelin T, Schellinger PD, Siebler M, Villringer A, Rother J 2002 Diffusion-weighted imaging in acute stroke-a tool of uncertain value? Cerebrovasc Dis 14:187-196

25. Rumpel H, Nedelcu J, Aguzzi A, Martin E 1997 Late glial swelling after acute cerebral hypoxia-ischemia in the neonatal rat: a combined magnetic resonance and histochemical study. Pediatr Res 42:54-59

26. Gass A, Niendorf T, Hirsch JG 2001 Acute and chronic changes of the apparent diffusion coefficient in neurological disorders-biophysical mechanisms and possible underlying histopathology. J Neurol Sci 186:S15-S23 
27. Sherwood NM, Timiras PS 1970 A stereotaxic atlas of the developing rat brain. University of California Press, Berkeley, Los Angeles; pp 1-209

28. Derugin N, Wendland M, Muramatsu K, Roberts TP, Gregory G, Ferriero DM, Vexler ZS 2000 Evolution of brain injury after transient middle cerebral artery occlusion in neonatal rats. Stroke 31:1752-1761

29. Daval JL, Pourie G, Grojean S, Lievre V, Strazielle C, Blaise S, Vert P 2004 Neonatal hypoxia triggers transient apoptosis followed by neurogenesis in the rat CA1 hippocampus. Pediatr Res 55:561-567

30. Nedelcu J, Klein MA, Aguzzi A, Martin E 2000 Resuscitative hypothermia protects the neonatal rat brain from hypoxic-ischemic injury. Brain Pathol 10:61-71

31. Wagner BP, Nedelcu J, Martin E 2002 Delayed postischemic hypothermia improves long-term behavioral outcome after cerebral hypoxia-ischemia in neonatal rats. Pediatr Res 51:354-360

32. Vannucci RC, Towfighi J, Vannucci SJ 1998 Hypoxic preconditioning and hypoxicischemic brain damage in the immature rat: pathologic and metabolic correlates. J Neurochem 71:1215-1220

33. Fernandez-Lopez D, Martinez-Orgado J, Nunez E, Romero J, Lorenzo P, Moro MA, Lizasoain I 2006 Characterization of the neuroprotective effect of the cannabinoid agonist WIN-55212 in an in vitro model of hypoxic-ischemic brain damage in newborn rats. Pediatr Res 60:169-173

34. Leker RR, Gai N, Mechoulam R, Ovadia H 2003 Drug-induced hypothermia reduces ischemic damage: effects of the cannabinoid HU-210. Stroke 34:2000-2006

35. Zhang M, Martin BR, Adler MW, Razdan RK, Jallo JI, Tuma RF 2007 Cannabinoid $\mathrm{CB}(2)$ receptor activation decreases cerebral infarction in a mouse focal ischemia/ reperfusion model. J Cereb Blood Flow Metab [Epub ahead of print]

36. Docagne F, Muñetón V, Clemente D, Ali C, Loría F, Correa F, Hernangómez M, Mestre L, Vivien D, Guaza C 2007 Excitotoxicity in a chronic model of multiple sclerosis: neuroprotective effect of cannabinoids through CB1 and CB2 receptor activation. Mol Cell Neurosci 34:551-561

37. Van Sickle MD, Duncan M, Kingsley PJ, Mouihate A, Urbani P, Mackie K, Stella N, Makriyannis A, Piomelli D, Davison JS, Marnett LJ, Di Marzo V, Pittman QJ, Patel KD, Sharkey KA 2005 Identification and functional characterization of brainstem cannabinoid CB2 receptors. Science 310:329-332

38. Ashton JC, Rahman RM, Nair SM, Sutherland BA, Glass M, Appleton I 2007 Cerebral hypoxia-ischemia and middle cerebral artery occlusion induce expression of the cannabinoid CB2 receptor in the brain. Neurosci Lett 412:114-117

39. Eljaschewitsch E, Witting A, Mawrin C, Lee T, Schmidt PM, Wolf S, Hoertnagl H, Raine CS, Schneider-Stock R, Nitsch R, Ullrich O 2006 The endocannabinoid anandamide protects neurons during CNS inflammation by induction of MKP-1 in microglial cells. Neuron 49:67-79

40. Howlett AC, Barth F, Bonner TI, Cabral G, Casellas P, Devane WA, Felder CC, Herkenham M, Mackie K, Martin BR, Mechoulam R, Pertwee RG 2002 International Union of Pharmacology. XXVII. Classification of cannabinoid receptors. Pharmacol Rev 54:161-202

41. Ortega-Gutierrez S, Molina-Holgado E, Guaza C 2005 Effect of anandamide uptake inhibition in the production of nitric oxide and in the release of cytokines in astrocyte cultures. Glia 52:163-168

42. Chen Y, Swanson RA 2003 Astrocytres and brain injury. J Cereb Blood Flow Metab 23:137-149

43. Chew LJ, Takanohashi A, Bell M 2006 Microglia and inflammation: impact on developmental brain injuries. Ment Retard Dev Disabil Res Rev 12:105-112

44. Golech SA, McCarron RM, Chen Y, Bembry J, Lenz F, Mechoulam R, Shohami E, Spatz M 2004 Human brain endothelium: coexpression and function of vanilloid and endocannabinoid receptors. Brain Res Mol Brain Res 132:87-92 